\title{
Counteracting incentive sensitization in severe alcohol dependence using deep brain stimulation of the nucleus accumbens: clinical and basic science aspects
}

\author{
Hans-Jochen Heinze ${ }^{1,2}$, Marcus Heldmann 1,2, Jürgen Voges ${ }^{1,3}$, Hermann Hinrichs ${ }^{1}$, Josep Marco-Pallares ${ }^{4,5}$, \\ Jens-Max Hopf ${ }^{1,2}$, Ulf J. Müller ${ }^{6}$, Imke Galazky' , Volker Sturm ${ }^{7}$, Bernard Bogerts ${ }^{6}$ and Thomas F. Münte ${ }^{4 *}$ \\ Department of Neurology, University of Magdeburg, Magdeburg, Germany \\ 2 Leibniz Institute of Neurobiology, Magdeburg, Germany \\ 3 Stereotactic Neurosurgery, University of Magdeburg, Magdeburg, Germany \\ 4 Department of Neuropsychology, University of Magdeburg, Magdeburg, Germany \\ 5 Institut d'Investigacions Biomèdiques de Bellvitge (IDIBELL), Barcelona, Spain \\ ${ }_{6}^{6}$ Department of Psychiatry, University of Magdeburg, Magdeburg, Germany \\ 7 Department of Stereotactic and Functional Neurosurgery, University of Cologne, Cologne, Germany
}

Edited by:

Olivier Bertrand, INSERM, France;

Lyon I University, France

Reviewed by:

Veerle Visser-Vandewalle,

Maastricht University Medical Center,

The Netherlands

Stephane Thobois,

Hôpital Neurologique Pierre

Wertheimer, France

*Correspondence:

Thomas F. Münte,

Department of Neuropsychology,

University of Magdeburg,

Gebäude 24, Universitätsplatz 2,

39106 Magdeburg, Germany.

e-mail: thomas.muente@medizin.

uni-magdeburg.de
The ventral striatum/nucleus accumbens (NAcc) has been implicated in the craving for drugs and alcohol which is a major reason for relapse of addicted people. Craving might be induced by drug-related cues. This suggests that disruption of craving-related neural activity in the NAcc may significantly reduce craving in alcohol-dependent patients. Here we report on preliminary clinical and neurophysiological evidence in three male patients who were treated with high frequency deep brain stimulation of the NAcc bilaterally. All three had been alcohol-dependent for many years, unable to abstain from drinking, and had experienced repeated relapses prior to the stimulation. After the operation, craving was greatly reduced and all three patients were able to abstain from drinking for extended periods of time. Immediately after the operation but prior to connection of the stimulation electrodes to the stimulator, local field potentials were obtained from the externalized cables in two patients while they performed cognitive tasks addressing action monitoring and incentive salience of drug-related cues. LFPs in the action monitoring task provided further evidence for a role of the NAcc in goal-directed behaviors. Importantly, alcohol-related cue stimuli in the incentive salience task modulated LFPs even though these cues were presented outside of the attentional focus. This implies that cue-related craving involves the NAcc and is highly automatic.

Keywords: local field potentials, intracranial recordings, deep brain stimulation, addiction, reward processing, action monitoring, nucleus accumbens

\section{INTRODUCTION}

Addiction, in particular to alcohol, is among the ten leading causes of disability in the world, placing an enormous emotional, social, and financial burden on society. Psychotherapeutic as well as pharmacotherapeutic interventions in addiction are not very successful, with relapse occurring in up to $80 \%$ of patients with severe alcohol addiction.

Clinicians, psychologists, and neurobiologists have tried to explain why addictive behaviors, once acquired, seem to be almost undeletably engraved in the addict's brain. The concept of "wanting" [used in quotes as, for example, by Berridge and Robinson (Berridge and Robinson, 2003; Robinson and Berridge, 2008)] has featured prominently in this regard. It refers to an underlying implicit and objective motivation process, incentive salience, and can be dissociated from hedonic aspects of addiction (termed "liking"). "Wanting" but not "liking" can explain compulsive drug intake even in situations in which the addict does not expect to experience a positive affect. On the neurobiological level, "wanting" has been explained by long-lasting sensitization changes in brain mesolimbic systems, sometimes also termed drug memory. The incentive-sensitization theory of addiction proposed by Berridge and Robinson combines neural sensitization and incentive salience concepts. It has been found that following alcohol or drug intake dopamine is released in the ventral striatum/nucleus accumbens (NAcc) (Koob and Le, 1997; Everitt et al., 2001; Everitt and Robbins, 2005; Koob and Le, 2008). Moreover, much like the mechanisms involved in reward prediction in animals, NAcc dopamine release attributes "incentive salience" to drug-associated cues (Robinson and Berridge, 2008). This cueinduced dopamine release, then, is thought to mediate "wanting" of alcohol or other drugs of abuse. Furthermore, through the alcoholinduced stimulation of dopamine release, a down-regulation of striatal dopamine $\mathrm{D} 2$ receptors occurs which may underlie the neural sensitization (Volkow et al., 1996). Indeed, alcohol-addicted patients with downregulated dopaminergic neurotransmission in the ventral striatum are at a higher risk for relapse (Dettling et al., 1995; Heinz et al., 1996; George et al., 1999).

Even though the view of the NAcc as the "Universal Addiction Site" (Dackis and O'Brien, 2001) may be an oversimplification, the NAcc is thus placed at a central place in orchestrating the events related to the "wanting" of alcohol on the one hand and drug-induced neural 
sensitization on the other hand. Anatomically, the NAcc receives inputs from the prefrontal cortex on the one hand and limbic structures such as the hippocampus and amygdala on the other (Groenewegen et al., 1999; Ikemoto and Panksepp, 1999). This circuitry allows for the integration of contextual information arising from hippocampus and emotional information coming from the amygdala with cognitive information supplied by the PFC in the selection of goal-directed behaviors in general (Grace, 2000) and behaviors related to drug "wanting" in particular, which is why the NAcc has been called a limbic-motor interface (Mogenson et al., 1980).

If the NAcc is a major brain site for the upholding of addictive behaviors, the question arises whether it might be possible to neurosurgically interfere with NAcc processing in order to alleviate drug addiction. Indeed, in a case series of 28 drug-addicted patients, Gao et al. (2003) reported on bilateral ablation of the NAcc core region in an effort to interfere with mesolimbic dopamine transmission. With complete remission in 7 patients, alleviation of withdrawal symptoms in 10 further patients, and poor outcome in 2 patients (outcome in 9 patients was not analyzed or lost for follow-up), the procedure was quite successful. The authors reported complications in six patients (personality change, $n=2$; temporary memory loss, $n=4$ ), however, which seems unreasonably high. Recently, Stelten et al. (2008) reviewed the current evidence on neurosurgical procedures in addiction. In addition to the Gao et al. (2003) study, a small number of studies investigated the possible beneficial effects of cingulotomy, hypothalamotomy, and ablation of the substantia innominata. Of these procedures, only cingulotomy has been performed in a reasonable number of patients with apparent success.

In other neuropsychiatric conditions, ablative interventions have been replaced by electric stimulation via permanently implanted electrodes (deep brain stimulation, DBS). DBS has the advantage of being adjustable, with stimulation parameters such as amplitude, frequency, width of the stimulating pulse, and (in multicontact electrodes) the location being under control of the clinician. Moreover, the procedure is nondestructive, carries a very low operative risk and is reversible, making it a very attractive treatment option. DBS treatment with high frequency stimulation is best established in Parkinson's disease (PD) in which the nucleus subthalamicus (Benabid et al., 2005; Benabid, 2007), globus pallidus internus (GPI), and ventral intermediate part of the thalamus (Diederich et al., 2008) have been the preferred targets. The GPI has also been targeted for dystonia. The DBS procedure has also been demonstrated to be a promising treatment of Cluster headache (Bussone et al., 2007; Bartsch et al., 2008) with the posterior inferior hypothalamus serving as a target. The hypothalamus has also been used as a target in severe obesity (Hamani et al., 2008).

With regard to psychiatric conditions, small clinical studies have used DBS in obsessive-compulsive disease (OCD), treatment resistant depression (TRD), and Tourette syndrome (TS), even though the status of the latter as a psychiatric disease might be debatable (Larson, 2008). While other target regions, such as the subgenual anterior cingulate gyrus for TRD (Mayberg et al., 2005), the anterior limb of the internal capsule (Nuttin et al., 2003; Abelson et al., 2005) and the subthalamic nucleus (Mallet et al., 2002, 2008) in OCD, and various regions of the thalamus and the globus pallidus in TS (Visser-Vandewalle et al., 2003;
Diederich et al., 2005; Houeto et al., 2005; Ackermans et al., 2006) have been targeted, the NAcc has been argued to be a suitable site for all of these conditions (Sturm et al., 2003; Kuhn et al., 2007b; Schlaepfer et al., 2008). For example, Schlaepfer et al. (2008) conceptualized "depression as a dysfunction of specific brain networks that mediate mood and reward signals, in particular, the cortical-limbic-thalamic-striatal network" and therefore argued for stimulation of the NAcc. In OCD, a series of four patients with active contacts in the NAcc has been published of whom three were reported to have had a nearly total recovery (Sturm et al., 2003). This small series is of particular importance as it has often been stressed that OCD and addiction have not only behavioral parallels, i.e., compulsive actions and compulsive drug intake, but also neurobiological parallels such as dopaminergic dysfunction in the ventral striatum (Perani et al., 2008).

With regard to the possible efficacy of DBS in addiction, a case report of Kuhn et al. (2007a) is particularly noteworthy. These authors treated a 54-year-old patient with severe anxiety disorder complicated by secondary depressive disorder and alcohol dependency by bilateral DBS of the NAcc with the aim to alleviate anxiety and depression. Whereas the patient experienced only a moderate reduction of his anxiety disorder and depression, he showed a remarkable reduction of alcohol intake such that 1 year after surgery he consumed alcohol only occasionally. This observation suggests that stimulation of the NAcc can in fact counteract the processes of incentive salience deemed to be important in alcohol dependence. This suggestion is further supported by a recent animal study carried out in rats (Vassoler et al., 2008). In this study, it was found that DBS of the NAcc (shell region) significantly attenuated the reinstatement of drug seeking. Control experiments showed that this effect was specific for the NAcc, as DBS of the dorsal striatum did not affect cocaine reinstatement. Also, the effect was specific for the drug, as DBS to the NAcc did not alter food seeking behavior. Thus, DBS to the NAcc in addiction appears to be specific both in terms of the stimulation location and in terms of the attenuation of "wanting" a specific substance.

Against this background our group decided to carry out a small clinical trial employing bilateral DBS in the NAcc in patients with severe and treatment resistant alcohol abuse. Obviously, the main objective of the study is to assess the efficacy and safety of DBS as a treatment option for severe addiction. In addition, DBS implantation offers also the opportunity to obtain electrophysiological recordings from NAcc and thus allows us to test predictions of the incentive salience theory of addiction. Indeed, it has been shown recently that recordings from the NAcc in the course of DBS-treatment of OCD (Münte et al., 2007, 2008) or TRD (Cohen et al., 2009) can be used to assess the structure's role in action monitoring (Münte et al., 2007) and reward processing (Cohen et al., 2009). Details regarding the target selection are described in Section "Neurosurgical Approach" and in Sturm et al. (2003).

To date, five patients have been enrolled in the study and have been followed up for a reasonable time-period. We will first briefly review the clinical results obtained so far and will then present some exemplary data from invasive recordings obtained perioperatively. We will briefly present qualitative clinical data from three patients and will also present some preliminary data regarding invasive recordings from the NAcc. 


\section{CLINICAL STUDY STUDY DESIGN}

The study is designed to include a total of 10 patients with therapy resistant alcohol dependency (DSM IV 303.90, ICD 10 F10.2). Inclusion criteria are: male gender, age 25-60 years, finished detoxification and subsequent period of abstinence of at least 2 weeks. Moreover, the patients are required to have demonstrated treatment failures of at least two inpatient programs of at least 6 month duration, failure of anti-craving substances (e.g., acamprosate, naltrexone), failure of community and self-help programs. Moreover, patients are required to have had at least 10 years of schooling and, in addition, a finished apprenticeship or higher education. Patient with less education are excluded at this point, because we wanted to ensure that the participants clearly understand the procedures and their associated risks and are also able to participate in the psychological tests before and after the implantation procedure. Patients are excluded, if they meet any of the following criteria: seizures during the detoxification phase, high score on neuroticism scales, antisocial personality disorder (as determined by a PCL-R score $>20$ ), clinically significant impairments on a neuropsychological test battery (including the German version of the Wechsler Adult intelligence test, a vocabulary test, the German version of the Rey Auditory Verbal Learning Test, the Trail Making Test, a German version of the Stroop test and a test of executive function: LPS-subtest 3). Further exclusion criteria were circumscribed brain damage or marked atrophy on MRI, alcohol-related personality change, and use of additional addictive substances. These inclusion/exclusion criteria were evaluated by an external physician specialized in the treatment of substance abuse.

At the point of writing this article, three patients have been successfully operated and followed up for more than 14 months. A fourth had been implanted but electrodes had to be removed because of an infectious complication.

\section{NEUROSURGICAL APPROACH}

Procedures to localize the ventro-caudo-medial accumbens have been worked out by one of us (Volker Sturm) together with the neuroanatomist Jürgen Mai, University of Düsseldorf, Germany (not yet published in detail). In brief, the stereotactic coordinates have been slightly changed compared to those first described by Sturm et al. (2003). The target was defined as the point $2 \mathrm{~mm}$ rostral to the anterior border of the anterior commissure at the level of the mid-sagittal plane, 3-4 mm ventral and 6-8 mm lateral of the midline. These are standard-coordinates which have to be modified according to the individual planning-MRI. An important landmark is the vertical limb of Broca's diagonal band which can be clearly visualized in coronal MRI-scans. The target was placed 2-2.5 mm lateral of this structure.

Using a deep fronto-lateral approach, the two distal contacts of the DBS-electrode are placed in the caudo-medial accumbens, the third contact within the transition-area to the medial border of the abutting internal capsule and the highest, i.e., fourth connection point in the most medial part of the capsule or in the transition area to the caudate. The contacts within the NAcc are placed in the caudo-medial part which according to histochemical criteria represents the remnant of the shell area in the primate. Different from rodents, the shell area has regressed in the primate and is no longer clearly distinguishable, except for the fact that it carries the typical receptors. It is densely equipped with D1-D3 and opiate receptors, as well as with receptors for a multitude of bioactive proteins and peptides. For reasons elaborated elsewhere (Sturm et al., 2003) the target area appears to be a highly relevant part of the mesolimbic reward-system and thus may constitute a suitable target from which addiction may be influenced.

Electrode-implantation (Medtronic Quad 3389) was performed in local anesthesia in the awake patients by Jürgen Voges after presurgical planning using high resolution T1-weighted MRI-scans. The correctness of the electrode-localization was been verified by stereotactic $\mathrm{x}$-ray imaging, fused with the planning-MRI in each case. Electrode leads were externalized postoperatively allowing electrical test stimulation with different parameters and the recording from the depth contacts in different psychological tasks. Subsequently, electrode-cables were connected to an impulse-generator located beneath the left pectoral muscle (Kinetra, Medtronic ${ }^{\varpi}$ ) similar to a cardiac pacemaker. Details regarding the stimulation protocols in the different patients can be found elsewhere (Müller et al., in press).

\section{PATIENTS}

More detailed clinical information is given in Müller et al. (in press). Three male patients participated in the study. Patient HM (age 36) had started to drink alcohol at age 12 and had a family history of alcoholism (father and two uncles). Prior to the operation the daily dose of alcohol amounted to two to three $0.7-1$ bottles of hard liquor per day. More than 60 inpatient detoxification treatments and three prolonged withdrawal therapies had been unsuccessful as well as treatment with acamprosate. The patient was implanted on October 5, 2007 and has been abstinent since then. There were no psychological changes after the operation. The patient reported to have no craving symptoms and that he is thus able to derive pleasure from daily activities of life. He has found a job and has established new social contacts.

Patient GM (age 37) had started to drink alcohol at age 11 and had a positive family history (father, mother, several other relatives). His first detoxification treatment was at age 15 and he took part in three prolonged withdrawal therapies of 3 months duration each. Acamprosate treatment had to be discontinued because of side effects. The longest period of abstinence prior to the operation had lasted 3 months during which the patient had experienced massive craving and intense reactions to alcohol-related cues. Following the operation (January 13, 2008) this patient experienced a period of hypomania which stopped after stimulation parameters were changed. The patient has been abstinent since the operation and reports a complete reduction of his reaction to alcohol-related cues and craving.

Patient TM (age 40) had been alcohol-dependent since age 18 and had a positive family history (father). Numerous withdrawal therapies had been unsuccessful. In 2005 he was sentenced to a jail sentence of 3 years during which he continued to drink. The preoperative MRI was unremarkable except for a small signal-intensity in the right temporal region, most likely a residual change after a contusion. The patient was operated on September 13, 2007 and showed no psychological abnormalities in the postoperative period. He was fully abstinent until September 2008. Subsequently, 
he has experienced short periods of relapse of 1-2 weeks duration (10 weeks in the past 16 months). The patient remarked that he had never felt as good as currently and reported a considerable reduction in his reaction to alcohol-related cues.

\section{INVASIVE ELECTROPHYSIOLOGY ELECTROPHYSIOLOGICAL RECORDING PROCEDURES}

Intracerebral recordings could be obtained after the operation, as the leads coming from the DBS-electrodes were externalized for several days before they were connected with the stimulator located beneath the pectoral muscle in a second small operation. The DBS electrode hosts four contacts (labeled $0,1,2,3$ ) located as specified in Section "Neurosurgical Approach." Bipolar recordings between two contacts of the electrode were obtained. The greatest distance between contacts $(0-3)$ is about $8 \mathrm{~mm}$.

In addition we also obtained surface EEG activity (Fz, F3, F4, $\mathrm{Cz}, \mathrm{Pz}, \mathrm{P} 3, \mathrm{P} 4$ referenced to the right mastoid process). All signals were acquired at a bandwidth of $0.01-100 \mathrm{~Hz}$ and data were sampled at 256 points/s. Data analysis was performed using EEGlab and ERPlab software running under Matlab. To assess differences between conditions in single patient data, we employed a nonparametric statistical test implemented in Matlab as suggested in Maris and Oostenveld (2007). In brief, given two experimental conditions (condition $\mathrm{A}$ and condition $\mathrm{B}$ ) we first computed the $\mathrm{t}$ statistic for them by using the mean and standard deviation among trials. We then randomly assigned the trials to one of the conditions maintaining the same number of trials per condition as in the experimental dataset and computed the test statistic for this random partition. We repeated this procedure 1000 times to obtain the histogram of the distribution of the single trials and calculated the proportion of random partition with a $t$ statistic greater than the one in the experimental condition. This proportion will be the $\mathrm{p}$-value of our effect. If the p-value is smaller than the critical alpha level (0.01) we concluded that the two conditions were significantly different. We employed this procedure for successive $20 \mathrm{~ms}$ time-windows from the onset of the stimulus until $600 \mathrm{~ms}$ poststimulus.

For the action monitoring study, we also examined timefrequency behavior of the electrical activity (see Marco-Pallares et al., 2008, for a more extensive description). To this end 4 -s epochs were generated (2000 ms before and after the stimulus-onset). Epochs exceeding $\pm 50 \mu \mathrm{V}$ in EOG or EEG were removed from further analysis. Single-trial data was convoluted using a complex Morlet wavelet:

$w\left(t, f_{0}\right)=\left(2 \pi \sigma_{t}^{2}\right)^{-1 / 2} e^{\frac{-t^{2}}{2 \sigma_{t}^{2}}} e^{2 i \pi f_{0} t}$

with the relation $f_{0} / \sigma_{f}$ [where $\left.\sigma_{f}=1 /\left(2 \pi \sigma_{t}\right)\right]$ set to 6.7 (TallonBaudry et al., 1997). Changes in time varying energy (square of the convolution between wavelet and signal) in the studied frequencies (from 1 to $40 \mathrm{~Hz}$; linear increase) with respect to baseline ( -300 to $0 \mathrm{~ms}$ with regard to stimulus onset) were computed for each trial and averaged separately for error and correct trials.

\section{ACTION MONITORING STUDY}

This study is a replication of an earlier experiment of out group (Münte et al., 2007) in a patient who underwent insertion of a DBS electrode in the right NAcc for the alleviation of severe OCD. We will just briefly summarize the motivation of the experiment here and refer the reader to our previous paper for more information.

Human actions are not error-free, which is why error-detection and correction are key cognitive processes. Both, electrophysiological and neuroimaging studies have provided evidence for a human action monitoring system. Importantly, response-locked event-related potentials (ERPs) feature a mediofrontal negativity in response to erroneous but not to correct button presses, termed the error-related negativity (ERN) that is believed to be generated in the anterior cingulate cortex (Falkenstein et al., 1990; Gehring et al., 1993; Luu and Tucker, 2001; Rodriguez-Fornells et al., 2002; Ullsperger and von Cramon, 2003; Rollnik et al., 2004). The ERN has been firmly established as a robust and reliable marker of error detection and has been used to assess changes in action monitoring in a number of neuropsychiatric diseases, such as depression, OCD or mediofrontal brain damage. Theoretical accounts have proposed that the ERN is driven by reinforcement learning signals originating in the mesencephalic dopamine system (MDS, Holroyd and Coles, 2002). This system modulates the activity of the anterior cingulate cortex. An error, detected by comparing an internal "efference copy" of an ongoing action with the action goal, is thought to lead to a phasic decrease in dopamine release and thus to the elicitation of an ERN in the ACC. In our earlier study, we had used a typical flanker task comprising the rapid presentation of letter-strings $(\mathrm{HHHHH}$, SSSS, HHSHH, SSHSS) with the center letter requiring a button press with either the left hand (for letter S) or the right hand (for letter $\mathrm{H}$ ). Importantly, incongruent flanker letters induce a high number of performance errors. Given that the midbrain dopaminergic system projects not only to the medial frontal cortex but also to NAcc which is richly innervated by dopaminergic input from the midbrain, we expected that an error signal should be detectable in the local field potential in the NAcc. This was in fact the case in a 39-year-old male patient with OCD who showed clear error-related modulations of the LFP which preceded surface activity by $40 \mathrm{~ms}$. We interpreted this finding as an indication for an involvement of NAcc in error processing and action monitoring and further proposed that the error information received by the NAcc might be used to weigh the information coming from limbic and prefrontal regions in order to shape goal directed behavior.

We repeated this experiment in patient GM. Unlike our earlier study in which recording was restricted to a short period during the actual operation and to the right NAcc (as no electrode was inserted on the left), we were able to record postoperatively for an extended period of time and from both sides. A total of 880 stimuli (350 congruent, duration $100 \mathrm{~ms}$, stimulus onset asynchrony 900-1100 ms) were presented over a period of $20 \mathrm{~min}$. The behavioral pattern seen in this patient was similar to that seen in many healthy controls: Reaction times were shorter for errors than for correct trials (311 ms errors vs. $409 \mathrm{~ms}$ correct) but similar for correct compatible and correct incompatible trials (414 ms compatible vs. $406 \mathrm{~ms}$ incompatible). Overall error-rate was $13.3 \%$ and thus within the range typically seen in this flanker paradigm. Incompatible trials led to a higher error-rate than compatible trials (12.2\% compatible vs. $17.8 \%$ incompatible). We also computed post-error slowing (PES) as an index of behavioral adaptation after a performance error (Marco-Pallares et al., 2008). The PES effect amounted to $72 \mathrm{~ms}$ which compares to $28 \mathrm{~ms}$ (SD 40) observed in a group of 41 normal 
subjects in our laboratory using the same paradigm. Averaged LFP and surface ERP data are shown in Figure 1.

The present findings corroborate our previous data obtained in a patient suffering from severe OCD which further strengthens our hypothesis that the NAcc is specifically involved in error processing and action monitoring (Münte et al., 2007). In our earlier investigation we had recorded intraoperatively from the tip of an exploration-electrode which was referenced to its guiding tube. The fact that similar findings were obtained in the current investigation using a bipolar montage between different contacts of the final DBS-electrode rules out the possibility that the activity is caused by volume conductance from distant sources (e.g., the ACC). Moreover, in the OCD patient we used cross-correlation analysis comparing depth and surface activity and demonstrated that error-related modulations in the NAcc preceded the surface activity by $40 \mathrm{~ms}$. A similar time-lag was also found in the present patient (39 ms, max. $r$ 0.28, right ACC contacts $0-3$ vs. surface) which further supports the local generation in NAcc. The time-lag can also be appreciated in the time-frequency analysis which is provided in Figure 2. In addition to an increase of theta-power which is clearly visible in the data from the $\mathrm{Ncl}$ accumbens contacts $0-3)$ as well as in the surface data ( $\mathrm{Cz}$ referenced to the mastoid process) it is also apparent that the theta response arises earlier in the depth recordings.

Action monitoring has conceptually been linked to reinforcement learning processes which are assumed to lead to phasic changes of dopaminergic activity emanating from the MDS and projecting to cortical structures including anterior cingulate cortex and the ventral striatum (Holroyd and Coles, 2002). The NAcc has been implicated with the integration of contextual (from hippocampus) and emotional (from amygdala) information with cognitive information supplied by the PFC (Goto and Grace, 2005; Grace et al., 2007). This circuit is important for the instantiation of goal-directed behaviors and has also been implicated in the drug seeking.

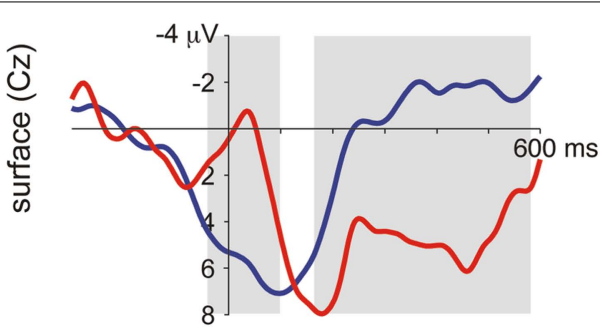

contact 0-3
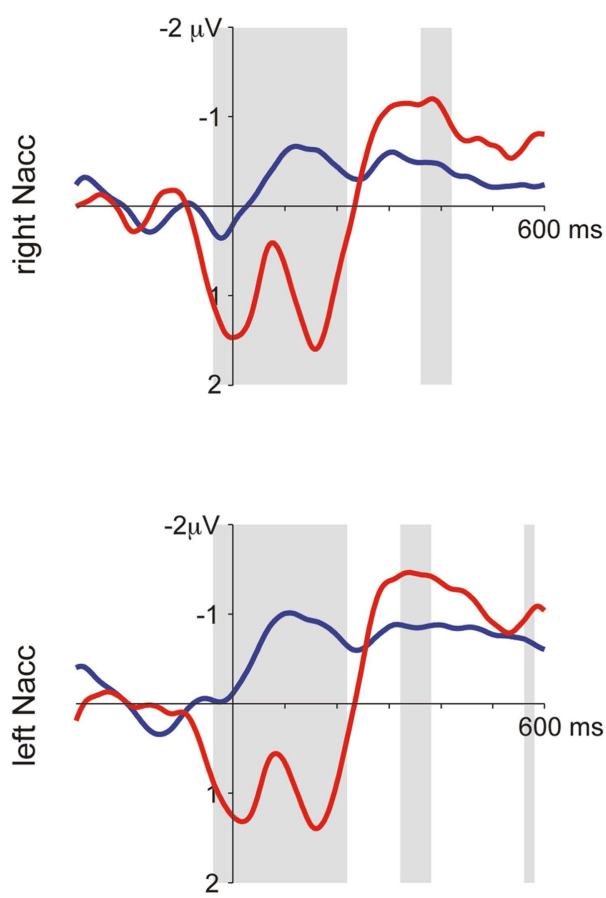

FIGURE 1 | Averaged LFP and surface ERP responses from Patient GM in the flanker task. Averaged surface event-related potentials (electrode $\mathrm{Cz}$ referenced against mastoid process) and bipolar averaged LFPs obtained time-locked to the erroneous motor response. A typical error-related negativity followed by the so-called error positivity was seen in the ERP (significant

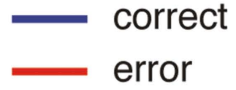

contact 2-3
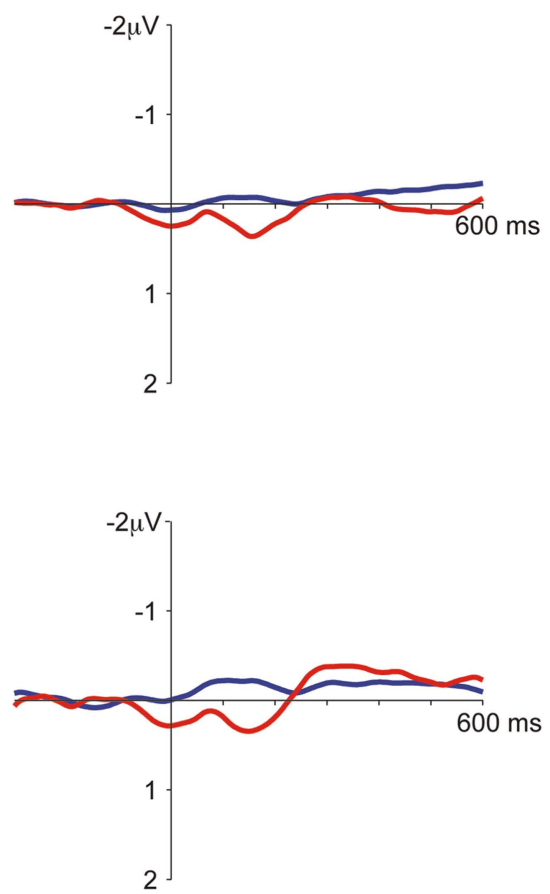

differences, $p<0.005$, as revealed by a bootstrapping procedure, between error and correct trials shaded in grey). In the NAcc on both sides similar error-related modulations were seen which were much more pronounced in the bipolar recordings between the two most distant contacts 0 and 3 than in the recordings between contacts 2 and 3 . Activity from both sides was very similar. 

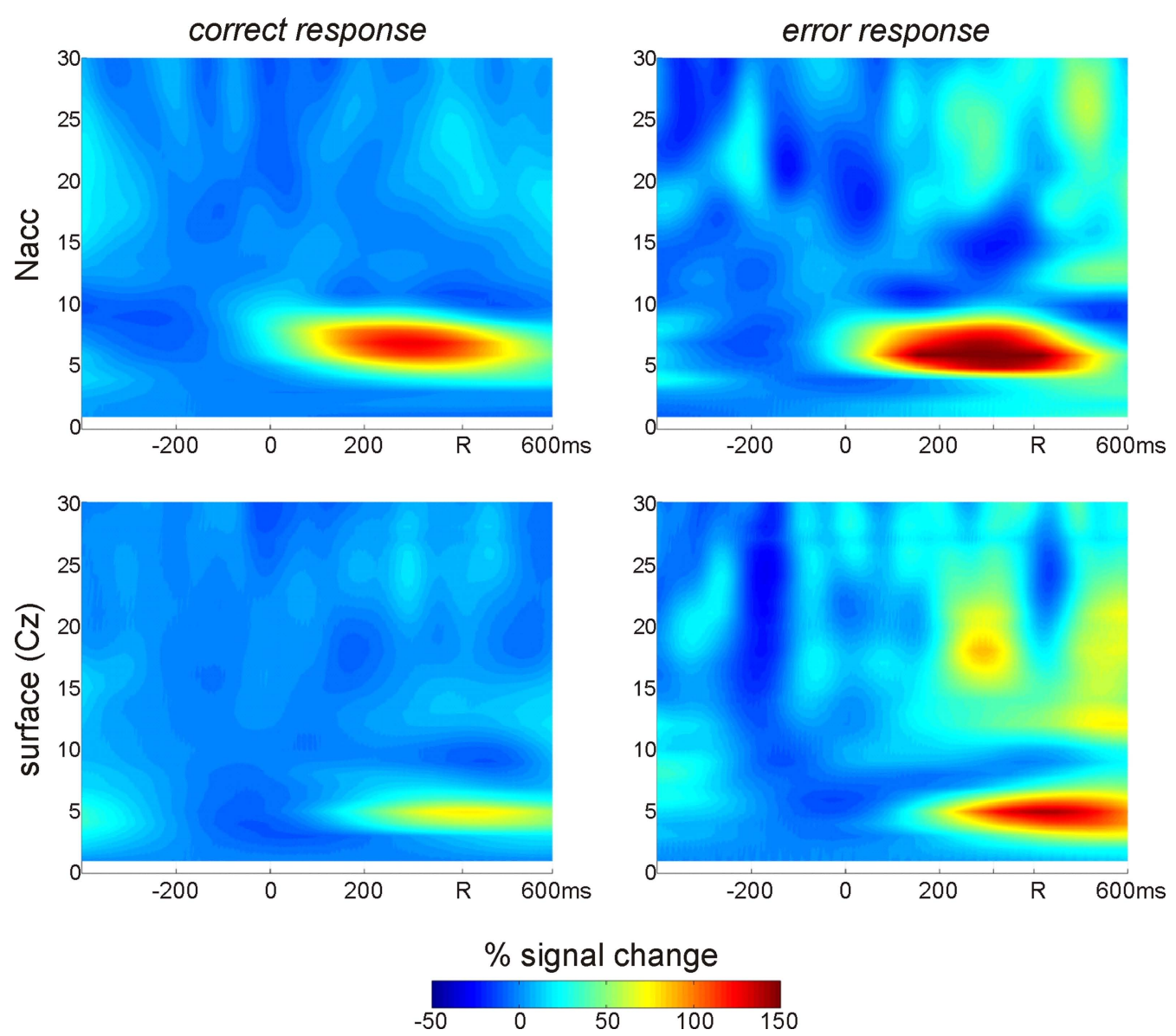

FIGURE 2 |Time frequency analysis of Ncl accumbens LFP and surface activity in patient GM. Two main findings emerge from the wavelet based time-frequency analysis: First, errors are associated with an increased power in the theta range compared to correct trials. Second, theta activity emerges considerably earlier in the depth recordings.

\section{INCENTIVE SALIENCE STUDY}

As pointed out in the introduction incentive salience might be one mechanism supporting drug addition. Drug-related stimuli may induce craving in addicted patients, prompting drug-seeking behavior. The neural mechanisms of craving have been investigated by presenting drug-related cues to addicted persons. In a number of studies cue-related activation in the ventral striatum has been observed (Kilts et al., 2001; Kilts et al., 2004; Myrick et al., 2004; David et al., 2005). For example, Braus et al. (2001) presented alcohol-associated cues to alcohol-dependent and control participants during functional MRI and observed activation of the ventral putamen in the former but not in the latter. Moreover, stronger activation to alcohol-related cues predicted relapse during the subsequent 3 months. Animal studies have revealed a complex network of brain areas involved in the motivational processes underlying addiction (for a recent review, see Kelley, 2004). Thus, it is not surprising that imaging studies on drug-cue induced craving have similarly revealed multiple brain areas activated including the perigenual and ventral anterior cingulate gyrus, the dorsolateral prefrontal and orbitofrontal cortex, insula, hippocampus, amygdala, and the ventral tegmental area (VTA, see Sinha and Li, 2007, for a review). As an example for VTA activation, Zijlstra et al. (2009) investigated detoxified opioid addicts and control subjects who were exposed to neutral, pleasant and heroin-related images while functional MRI was performed. Opioid-dependent subjects showed greater activation in the hippocampal region and subcortical limbic structures in response to heroin-related stimuli and moreover regression analyses showed a positive association between cueelicited craving and VTA activation in response to heroin-related stimuli.

Interestingly, Myrick et al. (2008) further strengthened the role of the ventral basal ganglia in cue-induced craving by investigating the effect of anti-craving drugs (naltrexone, ondansetron hydrochloride) on behavioral indices of cue-induced craving and associated ventral striatum activation. Treatment decreased craving for alcohol. Moreover, naltrexone alone, ondansetron alone or their combination decreased alcohol cue-induced activation of the ventral striatum.

Previous studies of cue-related craving have either used active or passive viewing of the drug-related cue stimuli. Passive viewing has been suggested to be preferable to active viewing (Heinz et al., 2004) as rating or other cognitive tasks have been shown to reduce affective neural responses (Taylor et al., 2003). However, even passive viewing may engage active evaluation processes by 
the participant. We therefore decided to use a visual search task in which alcohol-related cues occurred outside the focus of attention. The task was adapted from previous studies addressing visual selection processes (Woodman and Luck, 1999; Hopf et al., 2000). A typical stimulus is shown in Figure 3 and the task is explained in the accompanying legend.

Thus, the present experiment not only made the alcohol-related cue stimuli task-irrelevant but by presenting the target stimulus always contralaterally of the alcohol-related cue the latter was also presented outside of the attentional focus of the participant. If any differential activity for trials with alcohol-related vs. neutral distracter items is seen in the depth-activity from the NAcc in this paradigm, this would speak in favor of an automatic activation of the ventral striatum/NAcc by drug-related information.

This is in fact what we found in the two patients that so far have been investigated with this paradigm. As illustrated in Figure 4 showing LFP waveforms obtained from the left NAcc (bipolar recording between contacts $0-3$ ), a rather early difference between the waveforms obtained to stimulus-arrays with a neutral distracter and those with an alcohol-related distracter emerged. Unlike the action monitoring task, which showed very similar results for the left and right NAcc, we did not observe reliable differences between the two conditions in the right NAcc in the incentive salience task.

It has been suggested that dopamine release in the NAcc attributes "incentive salience" to drug-associated stimuli, increasing motivational value and attentional processing of drug-related cues (Robinson and Berridge, 2008). Moreover, such cue-induced dopamine release is thought to lead to drug "wanting" rather than drug "liking" (Berridge and Robinson, 2003). We postulate that the LFP changes in our two patients reflect cue-induced dopaminedependent activity. As previous functional imaging results (Heinz et al., 2004), these results underscore the role of the NAcc in mediating incentive salience. Our particular paradigm led to a strong focus of visual attention. The fact that alcohol-related cues were able to drive NAcc activity even when presented outside the attentional focus suggests that these cues are processed in a highly automatic fashion and thus might overwhelm the addicted person.

\section{GENERAL DISCUSSION}

As outlined in the introduction, relapse rates among human alcohol addicts are discouragingly high. For alcohol as well as other drugs such

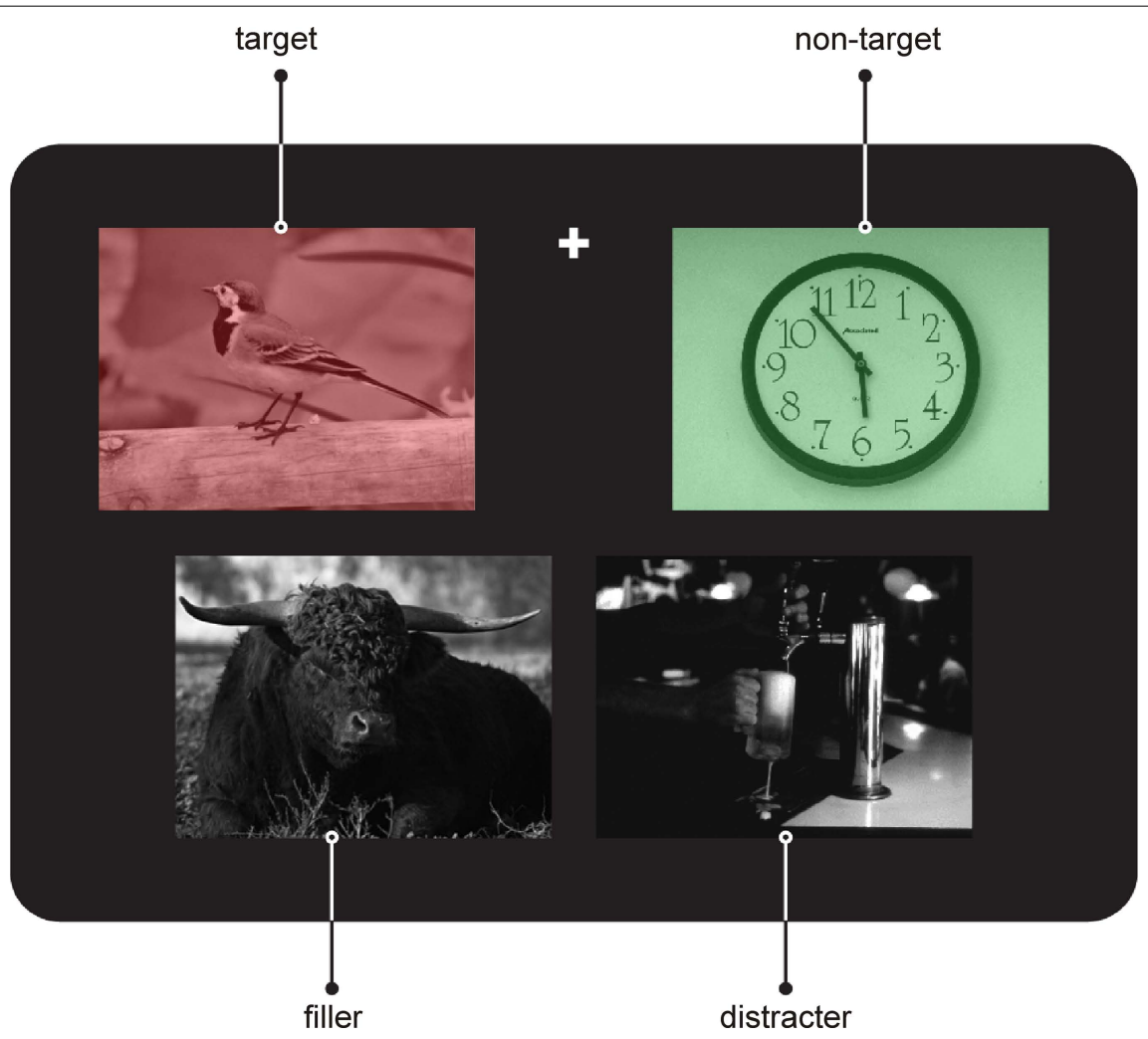

FIGURE 3 | Example for a stimulus from the incentive salience task. Each stimulus comprised an array of four pictures: one red, one green, and two gray colored. Colored and gray pictures were arranged in rows respectively and could occur in the upper or lower row. In any given run participants had to either attend to the red or the green stimuli in order to indicate by speeded button press with the right index or middle finger whether the depicted object could be classified as "living" or "non-living". All pictures were presented in the lower half of the visual field. The fixation cross was placed between the pictures of the upper row at their upper border. The participants had to fixate the fixation cross during the entire run. Importantly, gray distracter pictures, always presented contralaterally to the target picture, could be either neutral but showed always the contrary condition to the target picture (e.g., target "living, distracter "non-living," $50 \%$ ) or contain alcohol-related cues $(50 \%$, taken from Heinz et al., 2004). Patients participated in two experimental runs comprising 448 trials. The stimulus duration was $1000 \mathrm{~ms}$, and the interstimulus-interval was jittered between 2200 and 2500 ms. Identical sets of stimuli were presented in randomized order in both runs. Only the instruction regarding the target color changed. 

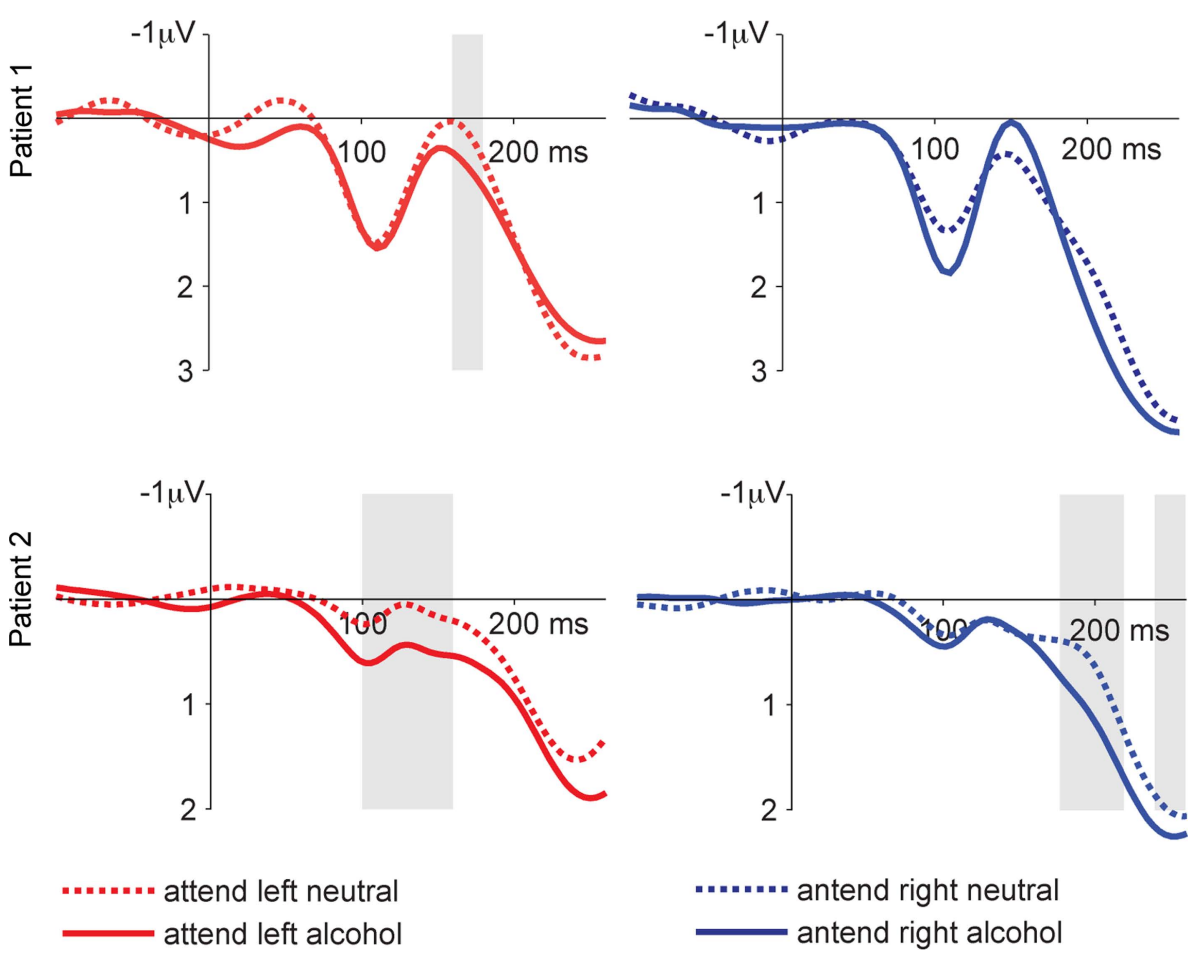

FIGURE 4 | LFPs from the incentive salience task. Shown are the responses from the left NAcc. We compare trials with an alcohol-related or neutral distracter stimulus on the side contralateral to the target stimulus. Shaded areas show significant differences between alcohol and neutral conditions as determined by the bootstrapping method (see text). This pattern of results suggests that alcohol-related cue information influences neural activity in the NAcc, even if this information is task irrelevant and presented outside the attentional focus. as cocaine, craving-induced relapse has been shown to be induced by stressful life events, environmental stimuli previously associated with drug taking, or re-exposure to the drug itself (Spealman et al., 1999; Goeders, 2002; Epstein et al., 2006; Schmidt et al., 2006).

In the introduction we have outlined a few arguments for a role of the NAcc in cue-induced craving. Also, in animal experiments making use of the reinstatement paradigm, which uses the administration of relatively low doses of a drug to reinstate drug-seeking behavior, it has been shown that the NAcc (in particular the shell region) is an important locus for reinstatement of drug-seeking behavior (Bachtell et al., 2005; Schmidt et al., 2005; Anderson et al., 2006; Schmidt et al., 2006).

That the shell rather than the core is important in addiction follows from the connectivity of these two parts of the NAcc. Whereas the core region interacts with the extrapyramidal motor system, the shell region is intimately connected with major relays of the limbic system. Because addiction is thought to be based on a dysregulation of a circuit comprising the dopaminergic midbrain, ventral striatum (including NAcc), amygdala and septal nuclei, as well as prefrontal and cingulate cortical areas, the shell region seems most important for addiction. It has to be pointed out that the coreshell-dichotomy has been elaborated mainly in rodents, whereas in man both parts are less well characterized (see also Section "Neurosurgical Approach"). Heimer (2000) has convincingly pointed out that the shell region is confined to the ventro-medial margin of the nucleus which explains our choice of the target location. The shell region receives a strong dopaminergic input from the
VTA and also input from the baso-lateral amygdala via the ventral amygdalofugal pathway (Alheid et al., 1998; de Olmos and Heimer, 1999). Its main output connections comprise the pallidum, dorsal striatum, mediodorsal thalamus, mesolimbic dopaminergic areas as well as frontal cortical areas including the cingulate cortex. Because of its position, NAcc may act as a gate-keeper weighting inputs from limbic and prefrontal areas under dopaminergic control to elicit goal directed behaviors. In addiction as well as in obsessivecompulsive disorder, inadequate function of the NAcc may result in obsessive repetition of addictive or obsessive behaviors.

This suggests that the disruption of NAcc activity might attenuate craving induced by drug-related cues or even low doses of the drug itself. The results of our pilot study give support to this notion both on clinical and on neurophysiological grounds: Clinically, all three patients who had experienced numerous relapses and had been unable to stay away from alcohol prior to the DBS operation improved greatly. Notably, all three patients reported a marked to nearly complete reduction of craving. Our neurophysiological results in the incentive salience paradigm suggest that the NAcc is indeed sensitive to alcohol-related cues. What is more, such drugrelated cues seem to be able to induce activity changes in the NAcc even when presented outside of the focus of visuo-spatial attention. This implies that the induction of craving is highly automatic. It is noteworthy that the effects of alcohol-related distracters were confined to the left NAcc. At present we have no explanation for this lateralization. Lateralized effects in the basal ganglia have been described with regard to pathological gambling, however, Cilia et al. 
(2008) examined resting state activity using 99Tc SPECT and found overactivity of a right hemisphere network comprising orbitofrontal cortex, hippocampus, amygdala, insula, and ventral pallidum. They concluded that pathological gambling is a "behavioral" addictive disorder induced by drug-induced mesocorticolimbic overstimulation. By contrast, Steeves et al. (2009), studying dopamine release in the ventral striatum using $[11 \mathrm{C}]$ raclopride PET found that PD patients with pathological gambling released dopamine bilaterally, whereas patients without pathological gambling showed only leftsided unilateral release in a gambling task. Thus, further studies are necessary to test whether lateralization patterns are stable in addiction. Recordings from the NAcc in the action monitoring paradigm further strengthen the role of the NAcc in the monitoring and control of behavior.

From a clinical point of view we consider all three patients to be responders at this point in time. A more definite assessment of

\section{REFERENCES}

Abelson, J. L., Curtis, G. C., Sagher, O., Albucher, R. C., Harrigan, M., Taylor, S. F., Martis, B., and Giordani, B. (2005). Deep brain stimulation for refractory obsessive-compulsive disorder. Biol. Psychiatry 57, 510-516.

Ackermans, L., Temel, Y., Cath, D., van der Linden, C., Bruggeman, R., Kleijer, M., Nederveen, P., Schruers, K., Colle, H., Tijssen, M. A., and VisserVandewalle, V. (2006). Deep brain stimulation in Tourette's syndrome: two targets? Mov. Disord. 21, 709-713.

Alheid, G. F., Beltramino, C. A., de Olmos, J.S., Forbes, M. S., Swanson, D. J., and Heimer, L. (1998). The neuronal organization of the supracapsular part of the stria terminalis in the rat: the dorsal component of the extended amygdala. Neuroscience 84, 967-996.

Anderson, S. M., Schmidt, H. D., and Pierce, R. C. (2006). Administration of the D2 dopamine receptor antagonist sulpiride into the shell, but not the core, of the nucleus accumbens attenuates cocaine priming-induced reinstatement of drug seeking. Neuropsychopharmacology 31, 1452-1461.

Bachtell, R. K., Whisler, K., Karanian, D., and Self, D. W. (2005). Effects of intranucleus accumbens shell administration of dopamine agonists and antagonists on cocaine-taking and cocaine-seeking behaviors in the rat. Psychopharmacology 183, 41-53.

Bartsch, T., Pinsker, M. O., Rasche, D., Kinfe, T., Hertel, F., Diener, H. C., Tronnier, V., Mehdorn, H. M., Volkmann, J., Deuschl, G., and Krauss, J. K. (2008). Hypothalamic deep brain stimulation for cluster headache: experience from a new multicase series. Cephalalgia 28 , 285-295.
Benabid, A. L. (2007). What the future holds for deep brain stimulation. Expert. Rev. Med. Devices 4, 895-903.

Benabid, A. L., Wallace, B., Mitrofanis, J., Xia, R., Piallat, B., Chabardes, S., and Berger, F. (2005). A putative generalized model of the effects and mechanism of action of high frequency electrical stimulation of the central nervous system. Acta Neurol. Belg. 105, 149-157.

Berridge, K. C., and Robinson, T.E. (2003). Parsing reward. Trends Neurosci. 26, 507-513.

Braus, D. F., Wrase, J., Grusser, S., Hermann, D., Ruf, M., Flor, H., Mann, K., and Heinz, A. (2001). Alcohol-associated stimuli activate the ventral striatum in abstinent alcoholics. J. Neural Transm. 108, 887-894.

Bussone, G., Franzini, A., Proietti, C. A., Mea, E., Curone, M., Tullo, V., Broggi, G., Casucci, G., Bonavita, V., and Leone, M. (2007). Deep brain stimulation in craniofacial pain: seven years' experience. Neurol. Sci. 28(Suppl. 2), S146-S149.

Cilia, R., Siri, C., Marotta, G., Isaias, I. U., De Gaspari, D., Canesi, M., Pezzoli, G., and Antonini A. (2008). Functional abnormalities underlying pathological gambling in Parkinson disease. Arch. Neurol. 65, 1604-1611.

Cohen, M. X., Axmacher, N., Lenartz, D., Elger, C. E., Sturm, V., and Schlaepfer, T. E. (2009). Good vibrations: cross-frequency coupling in the human nucleus accumbens during reward processing. J. Cogn. Neurosci. 21, 875-889.

Dackis, C. A., and O'Brien, C. P. (2001). Cocaine dependence: a disease of the brain's reward centers. J. Subst. Abuse Treat. 21, 111-117.

David, S. P., Munafo, M. R., Johansen-Berg, H., Smith, S. M., Rogers, R. D., Matthews, P. M., and Walton, R. T. (2005). Ventral striatum/

the clinical efficacy of the procedure will require a larger number of patients and an extended follow-up. Our preliminary results together with earlier findings in humans (Gao et al., 2003; Kuhn et al., 2007a) and animals (Vassoler et al., 2008) warrant further examination of DBS as a potential treatment in severe alcohol addiction, however. As illustrated by the intracerebral recordings from our current patients and argued by us in earlier publications (Münte et al., 2007, 2008; Münte and Kutas, 2008), invasive electrophysiology in behaving patients may provide a unique window into the physiological processes underlying reward processes in general and cue-induced craving in particular.

\section{ACKNOWLEDGEMENTS}

This work was supported by grants from the BMBF to Thomas F. Münte and Hans-Jochen Heinze, and grants from the DFG to Thomas F. Münte, Bernard Bogerts, and Hans-Jochen Heinze.

nucleus accumbens activation to smoking-related pictorial cues in smokers and nonsmokers: a functional magnetic resonance imaging study. Biol. Psychiatry 58, 488-494.

de Olmos, J., and Heimer, L. (1999). The concepts of the ventral striatopallidal system and extended amygdala. Ann. NY Acad. Sci 877, 1-31.

Dettling, M., Heinz, A., Dufeu, P., Rommelspacher, H., Graf, K. J., and Schmidt, L. G. (1995). Dopaminergic responsivity in alcoholism: trait, state, or residual marker? Am. J. Psychiatry 152, 1317-1321.

Diederich, N. J., Kalteis, K., Stamenkovic, M., Pieri, V., and Alesch, F. (2005). Efficient internal pallidal stimulation in Gilles de la Tourette syndrome: a case report. Mov Disord. 20, 1496-1499.

Diederich, N. J., Verhagen, M. L. Bakay, R. A., and Alesch, F. (2008). Ventral intermediate thalamic stimulation in complex tremor syndromes. Stereotact. Funct. Neurosurg. 86, 167-172.

Epstein, D. H., Preston, K. L., Stewart, J., and Shaham, Y. (2006). Toward a model of drug relapse: an assessment of the validity of the reinstatement procedure. Psychopharmacology 189, $1-16$.

Everitt, B. J., Dickinson, A., and Robbins, T. W. (2001). The neuropsychological basis of addictive behaviour. Brain Res. Brain Res. Rev 36, 129-138.

Everitt, B. J., and Robbins, T. W. (2005). Neural systems of reinforcement for drug addiction: from actions to habits to compulsion. Nat. Neurosci. 8, 1481-1489.

Falkenstein, M., Hohnsbein, J., Hoormann, J., and Blanke, L. (1990). Effects of errors in choice reaction task on the ERP under focused and divided attention. In Psychophysiological
Brain Research, C. H. M. Brunia, A.W. K. Gaillard and A Kok, eds (Tilburg, University Press), pp. 192-195.

Gao, G., Wang, X., He, S., Li, W., Wang, Q., Liang, Q., Zhao, Y., Hou, F., Chen, L., and Li, A. (2003). Clinical study for alleviating opiate drug psychological dependence by a method of ablating the nucleus accumbens with stereotactic surgery. Stereotact. Funct. Neurosurg. 81, 96-104.

Gehring, W. J., Goss, B., Coles, M. G. H., Meyer, D. E., and Donchin, E. (1993). A neural system for error-detection and compensation. Psychol. Sci. 4, 385-390.

George, D. T., Rawlings, R., Eckardt, M. J., Phillips, M. J., Shoaf, S. E., and Linnoila, M. (1999). Buspirone treatment of alcoholism: age of onset, and cerebrospinal fluid 5-hydroxyindolacetic acid and homovanillic acid concentrations, but not medication treatment, predict return to drinking. Alcohol. Clin. Exp. Res. 23, 272-278.

Goeders, N. E. (2002). Stress and cocaine addiction. J.Pharmacol.Exp. Ther. 301, 785-789.

Goto, Y., and Grace, A. A. (2005). Dopaminergic modulation of limbic and cortical drive of nucleus accumbens in goal-directed behavior. Nat. Neurosci. 8, 805-812.

Grace, A. A. (2000). Gating of information flow within the limbic system and the pathophysiology of schizophrenia. Brain Res. Brain Res. Rev. 31, 330-341.

Grace, A. A., Floresco, S. B., Goto, Y., and Lodge, D. J. (2007). Regulation of firing of dopaminergic neurons and control of goal-directed behaviors. Trends Neurosci. 30, 220-227.

Groenewegen, H. J., Wright, C. I., Beijer, A. V., and Voorn, P. (1999). Convergence and segregation of 
ventral striatal inputs and outputs. Ann. NY Acad. Sci. 877, 49-63.

Hamani, C., McAndrews, M.P., Cohn, M., Oh, M., Zumsteg, D., Shapiro, C. M., Wennberg, R. A., and Lozano, A. M. (2008). Memory enhancement induced by hypothalamic/fornix deep brain stimulation. Ann. Neurol. $63,119-123$.

Heimer, L. (2000). Basal forebrain in the context of schizophrenia. Brain Res. Rev. 31, 205-235.

Heinz, A., Dufeu, P., Kuhn, S., Dettling, M., Graf,K., Kurten, I., Rommelspacher, H., and Schmidt, L. G. (1996). Psychopathological and behavioral correlates of dopaminergic sensitivity in alcohol-dependent patients. Arch. Gen. Psychiatry 53, 1123-1128.

Heinz, A., Siessmeier, T., Wrase, J., Hermann, D., Klein, S., Grüsser, S. M., Flor, H., Braus, D. F., Buchholz, H. G., nder, G., Schreckenberger, M., Smolka, M. N., Sch, F., Mann, K., and Bartenstein, P. (2004). Correlation between dopamine $\mathrm{D} 2$ receptors in the ventral striatum and central processing of alcohol cues and craving. Am. J. Psychiatry 161, 1783-1789.

Holroyd, C. B., and Coles, M. G. (2002). The neural basis of human error processing: reinforcement learning, dopamine, and the error-related negativity. Psychol. Rev. 109, 679-709.

Hopf, J. M., Luck, S. J., Girelli, M., Hagner, T., Mangun, G. R.,Scheich, H., and Heinze, H. J. (2000). Neural sources of focused attention in visual search. Cereb. Cortex 10, 1233-1241.

Houeto, J. L., Karachi, C., Mallet, L., Pillon, B., Yelnik, J., Mesnage, V., Welter, M. L., Navarro, S., Pelissolo, A., Damier, P., Pidoux, B., Dormont, D., Cornu, P., and Agid, Y. (2005). Tourette's syndrome and deep brain stimulation. J. Neurol. Neurosurg. Psychiatry 76, 992-995.

Ikemoto, S., and Panksepp, J. (1999). The role of nucleus accumbens dopamine in motivated behavior: a unifying interpretation with special reference to reward-seeking. Brain Res. Rev. 31, 6-41.

Kelley, A. E. (2004). Memory and addiction: shared neural circuitry and molecular mechanisms. Neuron 44 , 161-179.

Kilts, C. D., Gross, R. E., Ely, T. D., and Drexler, K. P. G. (2004). The neural correlates of cue-induced craving in cocaine-dependent women. Am. J. Psychiatry 161, 233-241.

Kilts, C. D., Schweitzer, J. B., Quinn, C. K., Gross, R.E., Faber, T.L., Muhammad, F, Ely, T. D., Hoffman, J. M., and Drexler, K. P. G. (2001). Neural activity related to drug craving in cocaine addiction. Arch. Gen. Psychiatry 58, 334-341.
Koob, G. F., and Le, M. M. (1997). Drug abuse: hedonic homeostatic dysregulation. Science 278, 52-58.

Koob, G. F., and Le, M.M. (2008). Review. Neurobiological mechanisms for opponent motivational processes in addiction. Philos. Trans. R. Soc. Lond., B, Biol. Sci. 363, 3113-3123.

Kuhn, J., Lenartz, D., Huff, W., Lee, S., Koulousakis, A., Klosterkoetter, J., and Sturm, V. (2007a). Remission of alcohol dependency following deep brain stimulation of the nucleus accumbens: valuable therapeutic implications? J. Neurol. Neurosurg. Psychiatry 78, 1152-1153.

Kuhn, J., Lenartz, D., Mai, J. K., Huff, W., Lee, S. H., Koulousakis, A., Klosterkoetter, J., and Sturm, V. (2007b). Deep brain stimulation of the nucleus accumbens and the internal capsule in therapeutically refractory Tourette-syndrome. J. Neurol. 254, 963-965.

Larson, P. S. (2008). Deep brain stimulation for psychiatric disorders. Neurotherapeutics 5, 50-58.

Luu, P., and Tucker, D. M. (2001). Regulating action: alternating activation of midline frontal and motor cortical networks. Clin. Neurophysiol. 112, 1295-1306.

Mallet, L., Mesnage, V., Houeto, J. L., Pelissolo, A., Yelnik, J., Behar, C., Gargiulo, M., Welter, M. L., Bonnet, A. M., Pillon, B., Cornu, P., Dormont, D., Pidoux, B., Allilaire, J. F., and Agid, Y. (2002). Compulsions, Parkinson's disease, and stimulation. Lancet 360, 1302-1304.

Mallet, L., Polosan, M., Jaafari, N., Baup, N., Welter, M. L., Fontaine, D., du Montcel, S. T., Yelnik, J., Chereau, I., Arbus, C., Raoul, S., Aouizerate, B., Damier,P., Chabardes, S., Czernecki, V., Ardouin, C., Krebs, M. O., Bardinet, E., Chaynes, P., Burbaud, P., Cornu, P., Derost, P., Bougerol, T., Bataille, B., Mattei, V., Dormont, D., Devaux, B., Verin, M., Houeto, J. L., Pollak, P., Benabid, A. L., Agid, Y., Krack, P., Millet, B., and Pelissolo, A. (2008). Subthalamic nucleus stimulation in severe obsessive-compulsive disorder. N. Engl. J. Med. 359, 2121-2134.

Marco-Pallares, J.,Camara,E., Münte, T. F., and Rodriguez-Fornells, A. (2008). Neural mechanisms underlying adaptive actions after slips. J. Cogn. Neurosci. 20, 1595-1610.

Maris, E., and Oostenveld, R. (2007). Nonparametric statistical testing of EEG- and MEG-data. J. Neurosci. Methods 164, 177-190.

Mayberg, H. S., Lozano, A. M., Voon, V., McNeely, H. E., Seminowicz, D., Hamani, C., Schwalb, J. M., and Kennedy, S. H. (2005). Deep brain stimulation for treatment-resistant depression. Neuron 45, 651-660.

Mogenson, G. J., Jones, D. L., and Yim, C. Y. (1980). From motivation to action: functional interface between the limbic system and the motor system. Prog. Neurobiol. 14 69-97.

Müller UJ, Voges, J., Heinze, H. J., Galazky, I., Heldmann, M., Sturm, V., and Bogerts, B. (in press). Successful treatment of chronic resistant alcoholism by deep brain stimulation of nucleus accumbens: first experiences with three cases. Pharmacopsychiatry.

Münte, T., Heldmann, M., Hinrichs, H., Marco-Pallares, J., Krämer, U., Sturm, V., and Heinze, H. J. (2008) Contribution of subcortical structures to cognition assessed with invasive electrophysiology in humans. Front. Neurosci. 2, 72-78. doi: 10.3389/neuro.01.006.2008

Münte, T., Heldmann, M., Hinrichs, H., Marco-Pallares, J., Krämer, U., Sturm, V., and Heinze, H. J. (2007) Nucleus accumbens is involved in human action monitoring: evidence from invasive electrophysiological recordings. Front. Hum. Neurosci. 1, 11. doi:10.3389/neuro.09.011.2007

Münte, T. F., and Kutas, M. (2008). Capitalizing on deep brain stimulation: thalamus as a language monitor. Neuron 59, 677-680.

Myrick, H., Anton, R. F., Li, X., Henderson, S., Drobes, D., Voronin, K., and George, M. S. (2004). Differential brain activity in alcoholics and social drinkers to alcohol cues: relationship to craving. Neuropsychopharmacology 29, 393-402.

Myrick, H., Anton, R. F., Li, X., Henderson, S., Randall, P. K., and Voronin, K. (2008). Effect of naltrexone and ondansetron on alcohol cue-induced activation of the ventral striatum in alcohol-dependent people. Arch. Gen. Psychiatry 65, 466-475.

Nuttin, B. J., Gabriels, L. A., Cosyns, P. R., Meyerson, B. A., Andreewitch, S. Sunaert, S. G., Maes, A. F., Dupont, P. J., Gybels, J. M., Gielen, F., and Demeulemeester, H. G. (2003) Long-term electrical capsular stimulation in patients with obsessivecompulsive disorder. Neurosurgery 52, 1263-1272.

Perani, D., Garibotto, V., Gorini, A., Moresco, R. M., Henin, M., Panzacchi, A., Matarrese, M. Carpinelli, A., Bellodi, L., and Fazio, F. (2008). In vivo PET study of 5HT(2A) serotonin and $\mathrm{D}(2)$ dopamine dysfunction in drug-naive obsessivecompulsive disorder. Neuroimage 42 , 306-314.
Robinson, T. E., and Berridge, K. C. (2008). Review. The incentive sensitization theory of addiction: some current issues. Philos. Trans. R. Soc. Lond., B, Biol. Sci. 363, 3137-3146.

Rodriguez-Fornells, A., Kurzbuch, A. R., and Münte, T. F. (2002). Time course of error detection and correction in humans: neurophysiological evidence. J. Neurosci. 22, 9990-9996.

Rollnik, J. D., Schroder, C., RodriguezFornells, A., Kurzbuch, A. R., Dauper, J., Moller, J., and Münte, T. F. (2004). Functional lesions and human action monitoring: combining repetitive transcranial magnetic stimulation and event-related brain potentials. Clin. Neurophysiol. 115, 145-153.

Schlaepfer, T. E., Cohen, M. X., Frick, C., Kosel, M., Brodesser, D., Axmacher, N., Joe, A. Y., Kreft, M., Lenartz, and D., Sturm, V. (2008). Deep brain stimulation to reward circuitry alleviates anhedonia in refractory major depression. Neuropsychopharmacology 33, 368-377.

Schmidt, H. D., Anderson, S. M., Famous, K. R., Kumaresan, V., and Pierce, R. C. (2005). Anatomy and pharmacology of cocaine priminginduced reinstatement of drug seeking. Eur. J. Pharmacol. 526, 65-76.

Schmidt, H. D., Anderson, S. M., and Pierce, R. C. (2006). Stimulation of D1-like or D2 dopamine receptors in the shell, but not the core, of the nucleus accumbens reinstates cocaineseeking behaviour in the rat. Eur. J. Neurosci. 23, 219-228.

Sinha, R., and Li C. S. R. (2007). Imaging stress- and cue-induced drug and alcohol craving: association with relapse and clinical implications. DrugAlcohol Rev. 26, 25-31.

Spealman, R. D., Barrett-Larimore, R. L., Rowlett, J. K., Platt, D. M., and Khroyan, T.V.(1999).Pharmacological and environmental determinants of relapse to cocaine-seeking behavior. Pharmacol. Biochem. Behav. 64, 327-336.

Steeves, T. D., Miyasaki, J., Zurowski, M., Lang, A. E., Pellecchia, G., Van Eimeren, T., Rusjan, P., Houle, S., and Strafella, A. P. (2009). Increased striatal dopamine release in Parkinsonian patients with pathological gambling: a [11C] raclopride PET study. Brain 132, 1376-1385.

Stelten, B. M. L., Noblesse, L. H. M., Ackermans, L., Temel, Y., and VisserVandewalle, V. (2008). The neurosurgical treatment of addiction. Neurosurg. Focus 25, E5.

Sturm, V., Lenartz, D., Koulousakis, A. Treuer, H., Herholz, K., Klein, J.C., and Klosterkotter, J. (2003). The nucleus accumbens: a target for deep brain 
stimulation in obsessive-compulsiveand anxiety-disorders. J. Chem. Neuroanat. 26, 293-299.

Tallon-Baudry, C., Bertrand, O., Delpuech, C., and Pernier, J. (1997). Oscillatory gamma-band $(30-70 \mathrm{~Hz})$ activity induced by a visual search task in humans. J. Neurosci. 17, 722-734.

Taylor, S. F., Phan, K. L., Decker, L. R., and Liberzon, I. (2003). Subjective rating of emotionally salient stimuli modulates neural activity. Neuroimage 18 , 650-659.

Ullsperger, M., and von Cramon, D. Y. (2003). Error monitoring using external feedback: specific roles of the habenular complex, the reward system, and the cingulate motor area revealed by functional magnetic resonance imaging. J. Neurosci. 23, 4308-4314.
Vassoler, F. M., Schmidt, H. D., Gerard, M. E., Famous, K. R., Ciraulo, D. A., Kornetsky, C., Knapp, C. M., and Pierce, R. C. (2008). Deep brain stimulation of the nucleus accumbens shell attenuates cocaine priming-induced reinstatement of drug seeking in rats. J. Neurosci. 28, 8735-8739.

Visser-Vandewalle, V., Temel, Y., Boon, P., Vreeling, F., Colle, H., Hoogland, G., Groenewegen, H. J., and van der Linden, C. (2003). Chronic bilateral thalamic stimulation: a new therapeutic approach in intractable Tourette syndrome. Report of three cases. J. Neurosurg. 99, 1094-1100.

Volkow, N. D., Wang, G. J., Fowler, J. S., Logan, J., Hitzemann, R., Ding, Y. S., Pappas, N., Shea, C., and Piscani, K. (1996). Decreases in dopamine receptors but not in dopamine transporters in alcoholics. Alcohol. Clin. Exp. Res. 20, 1594-1598.

Woodman, G. F., and Luck, S. J. (1999). Electrophysiological measurement of rapid shifts of attention during visual search. Nature 400, 867-869.

Zijlstra, F., Veltman, D. J., Booij, J., van den Brink, W., and Franken, I. H. (2009). Neurobiological substrates of cue-elicited craving and anhedonia in recently abstinent opioid-dependent males. Drug Alcohol Depend 99 183-192.

Conflict of Interest Statement: The authors declare that the research was conducted in the absence of any commercial or financial relationships that could be construed as a potential conflict of interest.

Received: 17 May 2009; paper pending published: 26 June 2009; accepted:
12 August 2009; published online: 02 September 2009.

Citation: Heinze H-J, Heldmann M Voges J, Hinrichs H, Marco-Pallares J, HopfJ-M, Müller UJ, Galazky I, Sturm V, Bogerts B and Münte TF (2009) Counteracting incentive sensitization in severe alcohol dependence using deep brain stimulation of the nucleus accumbens: clinical and basic science aspects. Front. Hum. Neurosci. 3:22. doi: 10.3389/neuro.09.022.2009

Copyright (c) 2009 Heinze, Heldmann, Voges, Hinrichs, Marco-Pallares, Hopf, Müller, Galazky, Sturm, Bogerts and Münte. This is an open-access article subject to an exclusive license agreement between the authors and the Frontiers Research Foundation, which permits unrestricted use, distribution, and reproduction in any medium, provided the original authors and source are credited. 